\title{
Distribution of echinoderm larvae relative to the halocline of a salt wedge
}

\author{
Anna Metaxas ${ }^{1,2, *}$, Lauren S. Mullineaux ${ }^{1}$, Jay Sisson ${ }^{1}$ \\ ${ }^{1}$ Department of Biology, Woods Hole Oceanographic Institution, Woods Hole, Massachusetts 02543, USA \\ ${ }^{2}$ Present address: Department of Oceanography, Dalhousie University, Halifax, Nova Scotia B3H 4J1, Canada
}

\begin{abstract}
Aggregations of larvae of marine benthic invertebrates occur near physical and biological features of the water column, and can be the result of hydrodynamics, larval behavior, or a combination of the two. In this study, we examined the effect of flow on the vertical distribution of 4 -arm larvae of the sea urchin Lytechinus variegatus relative to a halocline. In the absence of flow, the larvae did not cross but aggregated at and below haloclines in which the salinity of the bottom layer was 31 and that of the top layer was either 21 or 25 . To test the effect of flow on this response, we generated a salt wedge in a $17 \mathrm{~m}$ flume, with 2 water layers of different salinity and opposite mainstream flow. Using the same treatments as in the absence of flow, we found that larval aggregation occurred below the halocline under low horizontal flow velocities. We propose that in the presence of laminar sheared flow, the larval vertical distribution relative to a halocline is modified by shear, which retains larvae near the halocline, resulting in a decreased probability of entrainment into the water layer of lower salinity.
\end{abstract}

KEY WORDS: Larval vertical distribution - Laminar sheared flow $\cdot$ Halocline $\cdot$ Behavioral response Echinoderm larvae $\cdot$ Salt wedge $\cdot$ Flume

Resale or republication not permitted without written consent of the publisher

\section{INTRODUCTION}

Patterns in larval distributions of marine benthic invertebrates, relative to physical features in the water column, have been observed in studies in the field and the laboratory (for review, see Metaxas 2001). In the field, larval aggregations in or immediately above or below pycnoclines have been recorded for several taxa (e.g. Tremblay \& Sinclair 1990a, Thiébaut et al. 1992, Raby et al. 1994), and the magnitude of aggregation has been positively related to the strength of stratification (Tremblay \& Sinclair 1990a,b). Increased larval concentrations also occur at convergences between fronts, or are associated with internal waves (Pineda 1994, 1999, Gallager et al. 1996, Shanks et al. 2000). These distributional patterns may result solely from hydrodynamics, or from their interactive effect with a larval behavioral response to changing environmental conditions.

In the laboratory, pronounced larval aggregations relative to sharp haloclines have been recorded for several taxa such as echinoplutei (Metaxas \& Young 1998b), ascidian tadpoles (Vázquez \& Young 1996), barnacle nauplii (Harder 1968), littorinid (Harder 1968) and bivalve veligers (Mann et al. 1991), and decapod zoeae (Sulkin et al. 1983). To maintain a particular position relative to the pycnocline, larvae may alternate periods of upward swimming with passive sinking, swim horizontally, or arrest swimming completely (McConnaughey \& Sulkin 1984, Mann et al. 1991, Metaxas \& Young 1998b). These studies demonstrate the important role of larval behavior in generating the observed aggregations under no flow; however, the relative importance of behavior under flow remains largely unknown.

It is well established that within the benthic boundary layer, larval delivery to appropriate settlement locations is mainly the result of hydrodynamics (Butman 1987). However, near the substratum (i.e. within $\mathrm{mm}$ to $\mathrm{cm}$ ), active selection of settlement sites by larvae is based on physical, chemical, and biological cues 
associated with the bottom (Mullineaux \& Butman 1991). Site selection may be achieved because of an increased ability of larvae to regulate their position in the reduced flow speeds (Butman 1987) or by increased retention resulting from vertical shear (Jonsson et al. 1991). Similar interactions between hydrodynamics and larval behavior may be operating at boundaries in the water column, such as pycnoclines and fronts (Metaxas 2001). Although they did not focus on boundaries, Fuchs et al. (2004) showed that, while in the water column, competent larvae of the mud snail Ilyanassa obsoleta ceased swimming above a threshold of turbulence intensity, resulting in their sinking to settlement locations.

Although swimming behavior does not contribute to larval horizontal dispersal in the ocean, it may play an important role in vertical dispersal relative to physical features in the water column (Metaxas 2001). For example, Pineda (1999) and Shanks et al. (2000) suggested that taxon-specific patterns of abundance relative to warm-water fronts were related to larval swimming ability. Unlike barnacle cyprids Pollicipes polymerus or larval shrimp Lucifer faxoni, which are strong swimmers, the weakly swimming cyphonautes of the bryozoan Membranipora sp. and veligers of the clam Mya arenaria did not aggregate at the fronts because they could not outswim the convergent flows (Pineda 1999, Shanks et al. 2000).

In this study, we examined the effect of flow on the vertical distribution of echinoid larvae Lytechinus variegatus relative to a halocline of an experimentally generated salt wedge in a flow tank in the laboratory. We hypothesized that in the absence of flow, larvae of L. variegatus will aggregate below the halocline, as shown in previous studies with other echinoid species. In a salt wedge, the dominant flow in each of 2 water layers with different salinity is in opposite directions. The flow at the interface between the 2 water layers can either be laminar and sheared, or turbulent. Larval vertical distribution relative to the density discontinuity in a salt wedge can be affected by (1) a larval behavioral response induced by cues related to the presence of a halocline and/or flow characteristics, such as vertical shear or turbulence; and/or (2) a compromised ability of larvae to sustain directed swimming under the particular flow characteristics.

\section{MATERIALS AND METHODS}

Larval rearing. Adult Lytechinus variegatus were induced to spawn by injecting $\sim 2 \mathrm{ml}$ of $0.55 \mathrm{M} \mathrm{KCl}$ through the peristomial membrane, and embryos were obtained by mixing sperm and eggs. Fertilization success, determined by the proportion of eggs (100 to
150 eggs scored per adult pair) with elevated perivitelline membranes, was 92 to $98 \%$.

Larvae were reared under a 12:12 h light:dark cycle (50 to $100 \mu$ Ein $\mathrm{m}^{-2} \mathrm{~s}^{-1}$ ), at $20^{\circ} \mathrm{C}$, in 3.51 jars containing $0.45 \mu \mathrm{m}$ filtered seawater, in practical salinity of 30 to 31 , and stirred continuously with a motorized paddle. The water in the culture jars was changed, and algae (5000 cells ml ${ }^{-1}$ ) were added every other day at a 50:50 mix (by cell number) of Dunaliella tertiolecta and Isochrysis galbana for the larvae used in the 'no flow' experiments and Isochrysis galbana for the larvae used in the 'flow' experiments. Although algal composition varied between the 2 sets of experiments because of availability, previous studies have shown only rare (2 of 12 species-treatment combinations) and small (3 to $10 \%$ ) differences in vertical distribution of larvae reared in single- and multi-species algal diets, with more larvae reared under single- than mixed-species crossing the halocline (Metaxas \& Young 1998b). In our experiments, we used larvae that were in the 4 -arm developmental stage and ranged in length between 520 and $610 \mu \mathrm{m}$. All experiments were done during the light part of the daily cycle.

‘No flow' experiments. We generated density discontinuities (haloclines) under 'no flow' in rectangular Plexiglas columns $(10 \times 10 \times 30 \mathrm{~cm})$. First, water of lower salinity was poured into the columns to a height of $10 \mathrm{~cm}$, and then the denser layer was siphoned to the bottom of the column until the water surface reached $20 \mathrm{~cm}$. We used 2 halocline treatments: in one, the salinity of the upper water layer was 21 , whereas in the other, it was 25 ; the salinity of the bottom layer was ambient at 31 for both treatment levels (hereafter $21 / 31$ and 25/31, respectively). To determine the exact position of the halocline, salinity was measured in $0.5 \mathrm{~cm}$ increments with a temperature-compensated refractometer (accuracy: $0.5 \mathrm{psu}$ ). We introduced 200 to 600 larvae to $3 \mathrm{~cm}$ above the bottom (hereafter ' $\mathrm{Cab}^{\prime}$ ') using a Pasteur pipette, and visually recorded their vertical position in $0.5 \mathrm{~cm}$ increments after $30 \mathrm{~min}$. We used 4 replicate columns for each halocline treatment and for control columns without a halocline (hereafter 31/31).

The height of the center of larval mass (ZCM) within a column was calculated using the equation:

$$
\mathrm{ZCM}=\sum p_{i} z_{i}
$$

where $p_{i}$ is the proportion of the total number of larvae observed in the $i$ th layer (40 layers of $0.5 \mathrm{~cm}$ ), and $z_{i}$ is the mid depth of the ith layer. Differences among treatments were explored with single-factor analysis of variance (ANOVA), and post hoc comparisons were made with Student-Newman-Keuls (SNK) tests. Levene's tests for homogeneity of variance indicated that 
no transformation was required for the analysis $\left(F_{2,9}=0.586, \mathrm{p}=0.576\right)$.

Design of the flow channel. A salt wedge was generated in the $17 \mathrm{~m}$ recirculating flow channel (flume) at the Rinehart Coastal Research Center, at the Woods Hole Oceanographic Institution, Massachusetts, USA (see Butman \& Chapman [1989] and Trowbridge et al. [1989] for a detailed description). The raceway of the flume is $17.3 \mathrm{~m}$ long, $0.3 \mathrm{~m}$ deep, and $0.6 \mathrm{~m}$ wide. The water collection basin consists of 2 large water reservoirs that are isolated from one another, a sump basin (16000 l) and a surrounding settling basin (16000 1). A $25 \mathrm{hp}$ centrifugal pump, controlled using an AC frequency drive, draws water from the sump basin and delivers it at a constant, user-selectable, flow rate to the raceway entrance region. At $17 \mathrm{~m}$ downstream from the entrance, vertical blinds operate as a weir and control the exiting volume and, thus, the depth of the water column in the raceway. The outflow can be directed into either chamber of the collection basin.

To generate a salt wedge in the raceway of the flume, bi-directional flow was established by pumping a layer of dense seawater upstream against a less dense seawater layer flowing downstream. Water of lower density was pumped by the $25 \mathrm{hp}$ centrifugal pump, from the sump basin to the upstream entrance of the raceway. A second, $0.75 \mathrm{hp}$ centrifugal pump was used to force a counter-current of denser seawater along the flume channel bottom. The counter-current flow of denser seawater was created with a customized nozzle (Fig. 1), placed at $15.5 \mathrm{~m}$ downstream and designed to diffuse the incident flow along the crossstream $(y, 0.604 \mathrm{~cm})$ and vertical $(z, 4.3 \mathrm{~cm})$ axes of the flume. The nozzle was $1.45 \mathrm{~m}$ long and $0.6 \mathrm{~m}$ wide to fit in the flume, made of acrylic plastic and placed immediately in front of the flume's weir. It had a baffled 'honeycomb' entrance region to the flume, made of multiple, thin-walled plastic tubes or cells (length: $25 \mathrm{~cm}_{\text {; }}$ sectional area: $1.33 \mathrm{~cm}^{2}$ ). Mixed water was removed from the flume through an arrangement of slots and a network of branched tubes located in the upper $5 \mathrm{~cm}$ of the nozzle. Tubing diameter between the pump and the nozzle was adjusted to achieve the desired flow rate.

To prevent it from migrating into the upstream entrance of the raceway, the boundary of the salt wedge was held in position at $7.5 \mathrm{~m}$ downstream by a $10 \mathrm{~cm}$ high, $1 \mathrm{~m}$ long ramp (Fig. 1). Return flow of the denser layer was forced by the ramp at the density discontinuity. Water at the discontinuity ( 10 cab) exited
Downstream end of flume $\longrightarrow$

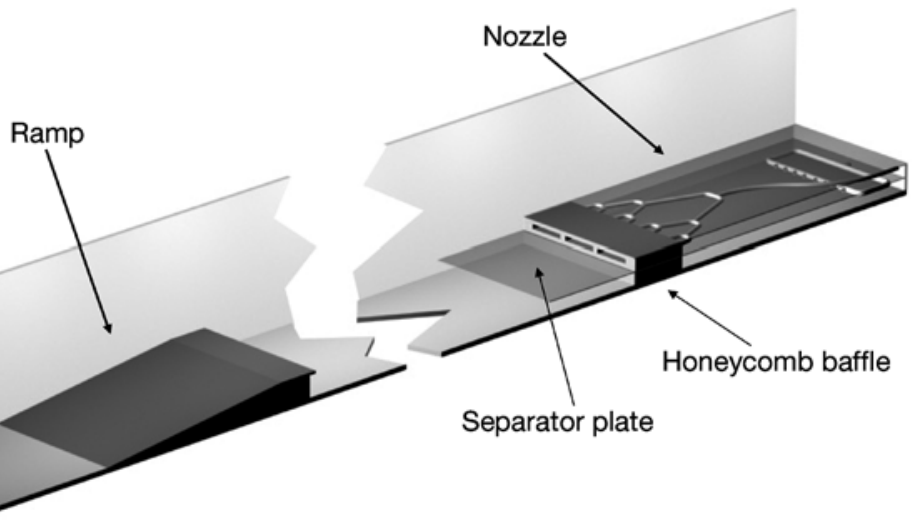

Upstream end of flume

. 1. Design of ramp and nozzle placed in a $17 \mathrm{~m}$ recirculating flume to $0.6 \mathrm{~m}$ wide), placed at $15.5 \mathrm{~m}$ downstream of the mainflow enamp ( $1 \mathrm{~m}$ long and $0.1 \mathrm{~m}$ high) was placed at $7.5 \mathrm{~m}$ downstream to hold the boundary of the salt wedge in position

the flume through the upper chamber of the nozzle. The water layer at $\mathrm{z}>10 \mathrm{cab}$ exited the raceway into the sump area through the regular exit. This design generated a salt wedge $8 \mathrm{~m}$ long with each water layer $10 \mathrm{~cm}$ high. The density structure of the experimental system remained stable for at least $1 \mathrm{~h}$ (unpubl. obs.).

'Flow' experiments. The same 2 haloclines (21/31 and 25/31) used in the 'no flow' experiments were also used in the 'flow' experiments. During preliminary flow characterization runs, the density structure of the water column was quantified with a microconductivity probe (Precision Measurement Engineering, model 125 Micro Scale Conductivity Temperature Instrument; accuracy: $0.0001 \mathrm{psu}$ and $0.01^{\circ} \mathrm{C}$ ) at 11 and $13 \mathrm{~m}$ alongstream, on 2 replicate runs for 21/31 and 25/31, respectively (each run involved the generation of a new salt wedge). To average density fluctuations arising from traveling wave crests at the discontinuity, 20 vertical profiles of salinity and temperature were measured at each alongstream distance for each replicate run, from 1.8 to $14.4 \mathrm{cab}$ at $1 \mathrm{~mm}$ intervals. We identified the boundaries of the halocline as the heights above (lower boundary) or below (upper boundary) which a monotonic change in salinity was observed for at least 5 consecutive mm. Concurrently, flow velocity was measured at 11 and $13 \mathrm{~m}$ alongstream with a 2-axis, forward-scatter, laser-Doppler velocimeter (LDV) to describe the flow structure of the salt wedge and derive relationships between the flow and density structures. Alongstream $(U)$ and vertical 
$(W)$ velocity were measured (mean calculated over a period of $240 \mathrm{~s}$ ) at $2,4,6,12$, and $14 \mathrm{cab}$, as well as at the boundaries of the density discontinuity. No flow measurements could be taken within the salinity discontinuity because of high refraction of the laser beams, but the vertical position of this optical refractive layer (ORL) was useful in estimating the position of the halocline.

Larvae ( 100000 to 150000$)$ were introduced into the denser water layer at $3 \mathrm{cab}$ and $11.5 \mathrm{~m}$ alongstream. Larval distribution was recorded at $10.8 \mathrm{~m}$ (the denser water layer was flowing upstream) with a Sony 3 chip CCD color video camera (model DXC-930) fitted with a $90 \mathrm{~mm}$ Fuzinon-TV.Z zoom lens (model VCL712BXEA). The field of view was $10 \mathrm{~cm}$ wide, $7 \mathrm{~cm}$ high, and $0.5 \mathrm{~cm}$ deep. The measurement volume was positioned in the center of the flow channel with its lower boundary at the bottom of the patch of larvae (2.5 cab for most trials). Distributions were recorded for $10 \mathrm{~min}$; longer records were not attempted because larvae were continually advected out of the measurement volume and abundances decreased over time (see 'Results'). Although this is a shorter observation period than in the 'no flow' experiments, previous studies (including ones that tracked individual larvae) have shown that larval distributions are attained within the first 5 to $10 \mathrm{~min}$ after introduction to experimental containers and remain stable thereafter (Metaxas \& Young 1998a,b, Burdett-Coutts \& Metaxas 2004). Homogeneous lighting was obtained by directing four $150 \mathrm{~W}$ reflector floodlights obliquely into the water column from 4 different directions, and reflection was minimized by covering the walls of the flume with black felt material.

Preliminary observations indicated that most (90 to $95 \%$ ) of the larvae detectable at the $10.8 \mathrm{~m}$ observation position were located within the $7 \mathrm{~cm}$ vertical view of the camera. Echinoid larvae typically swim upward until they encounter a discontinuity (Metaxas \& Young 1998a,b, Burdett-Coutts \& Metaxas 2004), and we assumed they would not descend more than $0.5 \mathrm{~cm}$ below their height of introduction. When images were recorded higher than $8.5 \mathrm{~cm}$ above bottom, fewer than 5 larvae were visible in the upper 1 to $2 \mathrm{~cm}$ of the ORL and in the layer above the ORL. We expect that larvae entering the layer above the ORL were quickly advected downstream and out of view.

For each replicate run of each halocline treatment, images were captured from the video at 1, 5, and $10 \mathrm{~min}$ after the larvae first reached the field of view. Images were imported into Adobe Photoshop to adjust contrast and brightness relative to a dark background. The image was then sub-divided into $1 \mathrm{~cm}$ horizontal segments, and the larvae in each segment were tagged and counted using Image Tool. The vertical position of the field of view (and, thus, of the individual $1 \mathrm{~cm}$ segments) in the flume was determined using an image with a scale placed in the field of view during the experiments. To maximize precision, 3 copies of each image were processed independently, and the number of larvae in each segment was averaged across the 3 replicate counts.

Direct measurement of the density discontinuity was not logistically possible during the larval experiment, because the generation of T-S profiles was extremely time-consuming and could not be completed together with the other measures within the $1 \mathrm{~h}$ period when the salt wedge was stable. Consequently, flow characteristics were quantified at $13 \mathrm{~m}$ alongstream, and the vertical location of the discontinuity at $11 \mathrm{~m}$ alongstream, where the larvae were observed, was inferred based on the preliminary flow characterization runs.

\section{RESULTS}

\section{Larval vertical distribution in 'no flow' experiments}

The experimentally generated haloclines were generally 1 to $3 \mathrm{~cm}$ thick, and thus quite sharp, and positioned between 9 and $12 \mathrm{cab}$ (Fig. 2). In the absence of a halocline, larvae swam directly to the water surface and remained there for the duration of the experimental period (Fig. 2). Larvae swam directly upwards (along the $z$-axis, no larvae deviating $>5^{\circ}$ from the axis) with a mean swimming speed of $0.122 \mathrm{~cm} \mathrm{~s}^{-1}$ $\left(\mathrm{SD}=0.034 \mathrm{~cm} \mathrm{~s}^{-1}, \mathrm{n}=75\right)$. The presence of a halocline inhibited larval vertical dispersal, and no larvae were found above $13 \mathrm{cab}$. Larvae showed a bimodal distribution, where 35 to $45 \%$ penetrated into the halocline and the remainder were found below it. Mean ZCM varied significantly among the 3 treatments (1-way ANOVA: $\left.F_{2,9}=40.47, \mathrm{p}<0.001\right)$; it was greater in the absence $(14.4 \pm 0.9 \mathrm{~cm}$, mean $\pm \mathrm{SE}, \mathrm{n}=4)$ than in the presence of a halocline $(7.8 \pm 0.6 \mathrm{~cm}$ and $6.9 \pm 0.4 \mathrm{~cm}$, for $21 / 31$ and $25 / 31$, respectively), but did not differ between 21/31 and 25/31 (SNK post hoc test, $p>0.05$ ). The ZCM was $2.0 \pm 0.6 \mathrm{~cm}(\mathrm{n}=4)$ and $3.6 \pm 0.6 \mathrm{~cm}$ below the lower boundary of the halocline in 21/31 and 25/31, respectively.

\section{Density structure and flow characterization of the water column}

Based on the microprobe measurements during the preliminary flow characterization runs, the thickness of the halocline did not differ alongstream between 11 and $13 \mathrm{~m}$ for $21 / 31$ and only differed by $0.65 \mathrm{~cm}$ for 


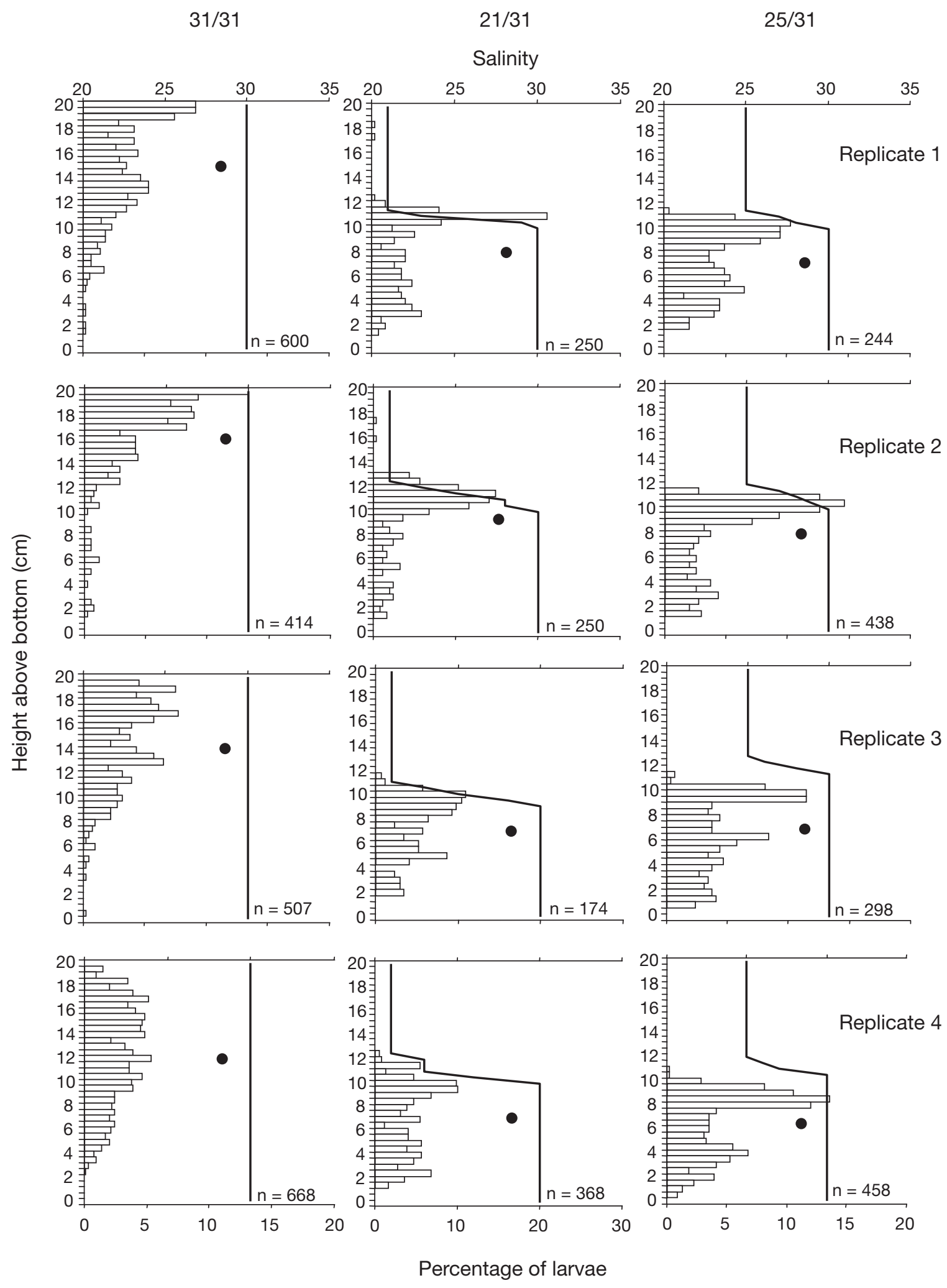

Fig. 2. Lytechinus variegatus. Vertical distribution of 4 -arm larvae in 3 salinity gradients $(31 / 31,21 / 31$, and 25/31) generated in Plexiglas columns in the laboratory. Bars indicate percentage of larvae at each $0.5 \mathrm{~cm}$ interval, and solid lines indicate salinity in each replicate ( $\mathrm{n}=$ total number of larvae). : mean height of center of mass of larval distribution 
$25 / 31$. However, both the lower and the upper boundaries of the halocline were $\sim 1 \mathrm{~cm}$ higher at 13 than $11 \mathrm{~m}$ for both halocline treatments (Fig. 3, Table 1). The thickness and the height of the lower boundary of the halocline did not vary significantly between 11 and $13 \mathrm{~m}$ alongstream or with halocline treatment, and there was no significant interaction between the 2 factors (Table 2). The height of the upper boundary of the halocline was greater at 13 than $11 \mathrm{~m}$ alongstream, but did not vary with halocline treatment, and there was no significant interaction between the 2 factors (Table 2).

Concurrent velocity measures taken during the preliminary runs indicated that the direction of the alongstream component $U$ was opposite in the 2 water layers, and its magnitude decreased towards the discontinuity both from the surface and the bottom (Fig. 3). No velocity measures were possible for a layer encompassing the density discontinuity because of high refraction of the laser beams due to mixing. This ORL was similar in thickness at 11 and $13 \mathrm{~m}$ alongstream for both halocline treatments (Fig. 3, Tables 1 \& 2). For 21/31, the vertical positions of both boundaries were similar between 11 and $13 \mathrm{~m}$, but were $\sim 2 \mathrm{~cm}$ higher at 13 than $11 \mathrm{~m}$ for 25/31 (Fig. 3, Table 1). There was no significant difference between alongstream distances or halocline treatments, and no significant interaction in the vertical position of either boundary of the ORL (Table 2). Neither $U$ nor $W$ measured at the lower boundary of the ORL varied significantly with alongstream distance or halocline treatment, and there was no significant interaction between the 2 factors (Table 2).

During the larval experiments, salinity was not measured, while we measured larval distribution at $11 \mathrm{~m}$ and velocity (including the position of the ORL) at $13 \mathrm{~m}$. Consequently, we estimated the vertical position of the halocline at $11 \mathrm{~m}$ based on 4 assumptions from the results of the preliminary flow characterization runs described above: (1) the ORL measured at $13 \mathrm{~m}$ completely encompassed (and in some cases was thicker than) the halocline measured at $11 \mathrm{~m}$ (Table 1); (2) the lower boundary of the ORL at $11 \mathrm{~m}$ was at the same position as measured at $13 \mathrm{~m}_{i}(3)$ the lower boundary of the halocline at $11 \mathrm{~m}$ was $\sim 1.5 \mathrm{~cm}$ above that of the ORL; and (4) the thickness of the halocline at $11 \mathrm{~m}$ was $\sim 2 \mathrm{~cm}$ for $21 / 31$ and $\sim 1.5 \mathrm{~cm}$ for $25 / 31$. We also assumed that the velocities below the lower boundary of the ORL at $11 \mathrm{~m}$ were approximately the same as those measured at $13 \mathrm{~m}$. We could then relate the observed larval distributions to the salinity (halocline) and flow structure of the water column at $11 \mathrm{~m}$. Although differences between 11 and $13 \mathrm{~m}$ in the position of the lower boundary of the ORL were not significant, our assumption that they were located at the same height potentially introduced as much as $0.5 \mathrm{~cm}$ error into the estimated height of the halocline for $21 / 31$ and $2.0 \mathrm{~cm}$ for $25 / 31$. The implications of this uncertainty are evaluated in the 'Discussion'.

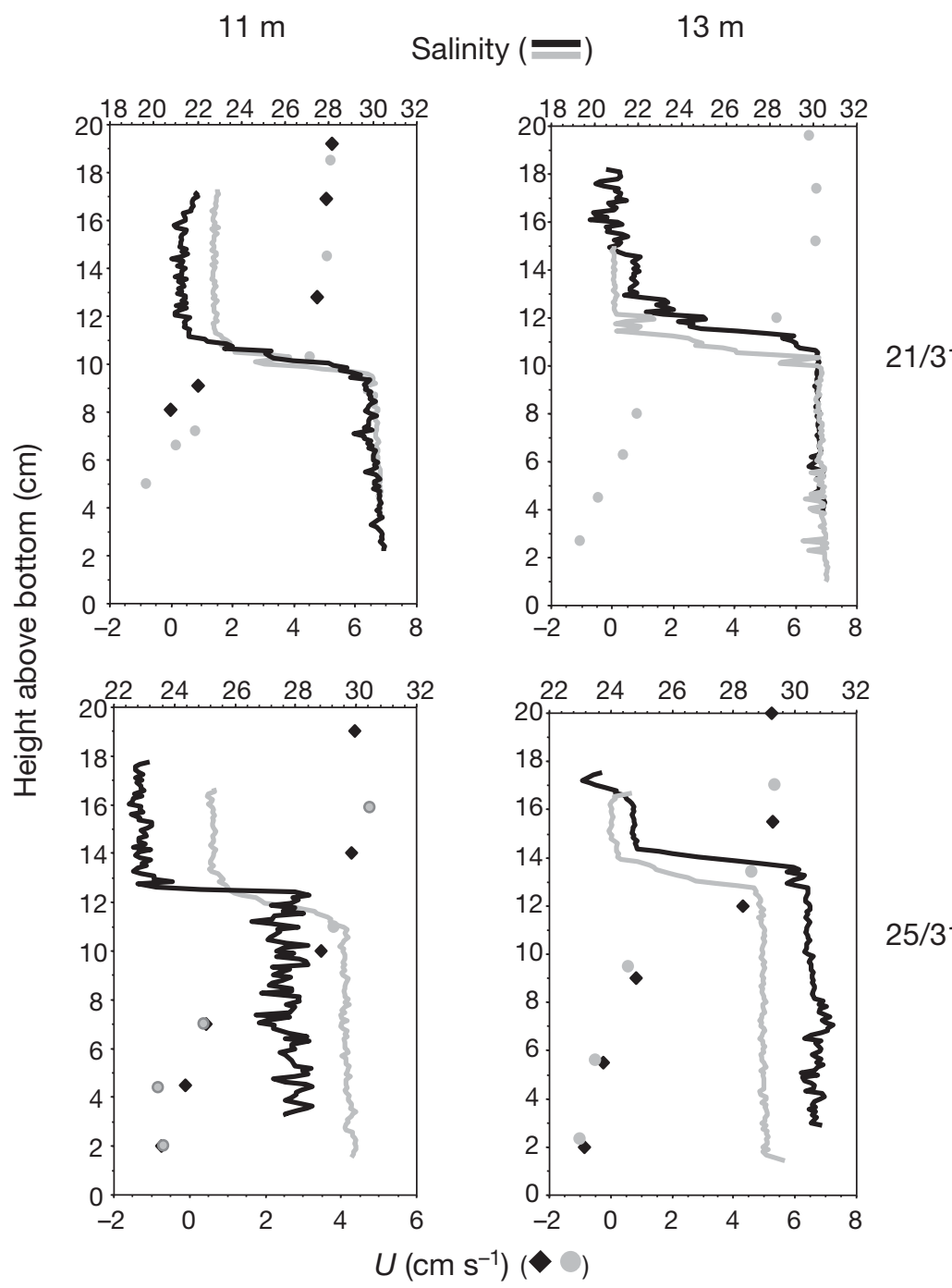

Fig. 3. Profiles of mean salinity (measured with a T-S microprobe) and mean alongstream velocity (measured with an LDV) at 2 alongstream distances in salt wedges of each of 2 salinity gradients $(21 / 31,25 / 31)$, generated in a $17 \mathrm{~m}$ flume. For each run, 20 vertical profiles of salinity were averaged at each alongstream distance. Symbols and lines of same shading indicate concurrent measures for each of 2 runs 
Table 1. Characteristics of density and flow structure of a density discontinuity associated with a salt wedge generated in a $17 \mathrm{~m}$ flume in the laboratory, collected concurrently during initial flow characterization runs. (cab $=\mathrm{cm}$ above the bottom). $\mathrm{n}=2$ for all cases where SD is calculated. No LDV data were available at $13 \mathrm{~m}$ for one of the 21/31 preliminary runs, and thus a single value is given. $U=$ alongstream velocity; $W=$ vertical velocity

\begin{tabular}{|c|c|c|c|c|}
\hline \multirow[b]{2}{*}{ Parameter } & \multicolumn{2}{|c|}{$-21 / 31$} & \multicolumn{2}{|c|}{$25 / 31$} \\
\hline & $\begin{array}{c}11 \mathrm{~m} \\
\text { mean } \pm \mathrm{SD}\end{array}$ & $\begin{array}{c}13 \mathrm{~m} \\
\text { mean } \pm \mathrm{SD}\end{array}$ & $\begin{array}{c}11 \mathrm{~m} \\
\text { mean } \pm \mathrm{SD}\end{array}$ & $\begin{array}{c}13 \mathrm{~m} \\
\text { mean } \pm \mathrm{SD}\end{array}$ \\
\hline Thickness of halocline $(\mathrm{cm})$ & $2.0 \pm 0.1$ & $2.0 \pm 0.8$ & $1.1 \pm 0.9$ & $1.7 \pm 0.3$ \\
\hline Lower boundary of halocline (cab) & $9.5 \pm 0.1$ & $10.5 \pm 0.1$ & $10.5 \pm 0.9$ & $11.7 \pm 0.7$ \\
\hline Upper boundary of halocline (cab) & $11.5 \pm 0.2$ & $12.4 \pm 0.9$ & $11.5 \pm 0.00$ & $12.9 \pm 0.4$ \\
\hline Thickness of the optical refraction layer (ORL; $\mathrm{cm})$ & $3.4 \pm 0.4$ & 4.0 & $3.5 \pm 0.7$ & $3.7 \pm 1.0$ \\
\hline Lower boundary of ORL (cab) & $8.2 \pm 1.3$ & 8.0 & $7.0 \pm 0.0$ & $9.0 \pm 0.0$ \\
\hline Upper boundary of ORL (cab) & $11.6 \pm 1.8$ & 12.0 & $10.5 \pm 0.7$ & $12.7 \pm 1.0$ \\
\hline$U$ at lower boundary of ORL $\left(\mathrm{cm} \mathrm{s}^{-1}\right)$ & $0.83 \pm 0.06$ & 0.80 & $0.42 \pm 0.04$ & $0.72 \pm 0.17$ \\
\hline$U$ at upper boundary of ORL $\left(\mathrm{cm} \mathrm{s}^{-1}\right)$ & $4.65 \pm 0.18$ & 5.37 & $3.65 \pm 0.23$ & $4.46 \pm 0.21$ \\
\hline$W$ at lower boundary of ORL $\left(\mathrm{cm} \mathrm{s}^{-1}\right)$ & $-0.015 \pm 0.042$ & 0.107 & $0.015 \pm 0.014$ & $0.016 \pm 0.016$ \\
\hline$W$ at upper boundary of ORL $\left(\mathrm{cm} \mathrm{s}^{-1}\right)$ & $-0.033 \pm 0.027$ & -0.033 & $-0.018 \pm 0.019$ & $-0.048 \pm 0.032$ \\
\hline
\end{tabular}

Table 2. Results of 2-way ANOVA of effects of alongstream position $(11,13 \mathrm{~m})$ and intensity of the halocline $(21 / 31,25 / 31)$ on salt wedge characteristics, including the vertical positions of the halocline and optical refraction layer (ORL), and flow velocities at the lower ORL boundary ( $U=$ alongstream velocity; $W=$ vertical velocity)

\begin{tabular}{|llccc|}
\hline \multicolumn{2}{|c}{ Characteristic } & $\begin{array}{c}\text { Position } \\
\left(F_{(\mathrm{df})}, \mathrm{p}\right)\end{array}$ & $\begin{array}{c}\text { Halocline } \\
\left(F_{(\mathrm{df})}, \mathrm{p}\right)\end{array}$ & $\begin{array}{c}\text { Interaction } \\
\left(F_{(\mathrm{df})}, \mathrm{p}\right)\end{array}$ \\
\hline Halocline & Thickness & $0.550_{(1,4)}, 0.500$ & $1.73_{(1,4)}, 0.260$ & $0.550_{(1,4)}, 0.500$ \\
& Lower boundary & $7.07_{(1,4)}, 0.056$ & $7.07_{(1,4)}, 0.056$ & $0.131_{(1,4)}, 0.735$ \\
& Upper boundary & $11.9_{(1,4)}, 0.026$ & $0.562_{(1,4)}, 0.495$ & $0.360_{(1,4)}, 0.581$ \\
ORL & & & & \\
& Thickness & $0.463_{(1,3)}, 0.545$ & $0.029_{(1,3)}, 0.876$ & $0.116_{(1,3)}, 0.756$ \\
& Lower boundary & $2.28_{(1,3)}, 0.229$ & $0.015_{(1,3)}, 0.910$ & $3.07_{(1,3)}, 0.178$ \\
& Upper boundary & $1.83_{(1,3)}, 0.269$ & $0.032_{(1,3)}, 0.870$ & $0.798_{(1,3)}, 0.437$ \\
$W$ & & & & \\
$W$ & & $2.38_{(1,3)}, 0.220$ & $8.94_{(1,3)}, 0.058$ & $4.13_{(1,3)}, 0.135$ \\
& & $8.09_{(1,3)}, 0.065$ & $1.95_{(1,3)}, 0.257$ & $7.83_{(1,3)}, 0.068$ \\
\hline
\end{tabular}

\section{Larval vertical distribution in 'flow' experiments}

In the presence of flow, larvae aggregated below the halocline in all replicates of both 21/31 and 25/31 treatments (Figs. 4 \& 5). The vertical distribution changed over the first $5 \mathrm{~min}$ after larval introduction, when larvae ascended towards the lower boundary of the halocline, but remained constant after that. Overall, the number of larvae in the images decreased ( $\mathrm{n}$ values in Figs. 4 \& 5) over the observational period, greatly between 1 and $5 \mathrm{~min}$, and less so between 5 and $10 \mathrm{~min}$. Over the period of $5 \mathrm{~min}$ after introduction, larvae could have travelled the total horizontal distance between the release point and the upstream end of the salt wedge at the ramp $(4 \mathrm{~m})$ as passive particles at speeds as slow as $0.022 \mathrm{~cm} \mathrm{~s}^{-1}$. Consequently, we expect that larval horizontal distribution below the interface no longer varied horizontally along the flume after these first $5 \mathrm{~min}$, and the smaller reduction in larval numbers observed between 5 and 10 min was most likely due to entrainment into the interface. Analysis by 2-way (larval position, time) loglinear models indicated that larval vertical distribution (of frequencies at each height above bottom) was dependent on time after introduction in 4 out of 5 replicates for $21 / 31$, and in all replicates for 25/31 (Figs. 4 \& 5; replicates were not homogeneous and could not be pooled in a single analysis). Mean ZCM increased significantly over time (repeated measures 2-way ANOVA: $F_{1.4,11.1}=21.1$, $\mathrm{p}<0.001$, Greenhouse-Geisser correction), but it did not vary between halocline treatments $\left(F_{1,8}=0.130\right.$, $\mathrm{p}=0.727)$, and there was no significant interaction between the 2 factors $\left(F_{1.4,11.1}=0.445, \mathrm{p}=0.581\right.$, Greenhouse-Geisser correction; Fig. 6). At 10 min after introduction, mean ZCM was $3.2 \pm 0.3 \mathrm{~cm}( \pm \mathrm{SE}, \mathrm{n}=5)$ and $3.9 \pm 0.3 \mathrm{~cm}$ below the lower boundary of the halocline in 21/31 and 25/31, respectively. Larval aggregation below the halocline also coincided with the regions where alongstream velocity $U$ was low for both $21 / 31$ and 25/31, and ranged between -1.5 and $+1.5 \mathrm{~cm} \mathrm{~s}^{-1}$ (Figs. 4 \& 5).

Overall, the residence time of larvae within our experimental system was relatively short. We estimated rate of larval removal from the flume through entrainment into the interface, by positioning a siphon (2.54 cm i.d.) at $10 \mathrm{cab}$ and $15.3 \mathrm{~m}$ alongstream and sampling a known volume of water (90 to $225 \mathrm{ml}$ ) over a measured time period (810 to $1439 \mathrm{~s}$ ). Ten to $20 \mathrm{~min}$ after introduction, $31 \pm 12 \%$ (mean $\pm \mathrm{SE}, \mathrm{n}=5$ ) and $23 \pm 4 \%$ of larvae added to the flume (for 21/31 and $25 / 31$, respectively) were collected near the exit. 
21/31 $1 \mathrm{~min}$
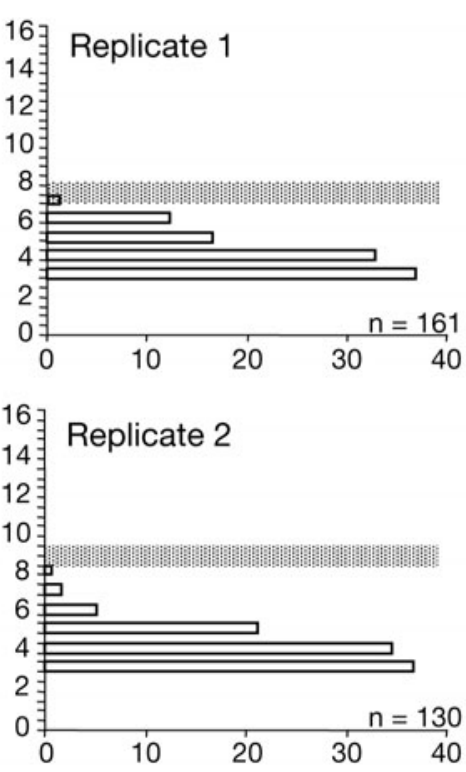

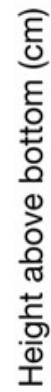
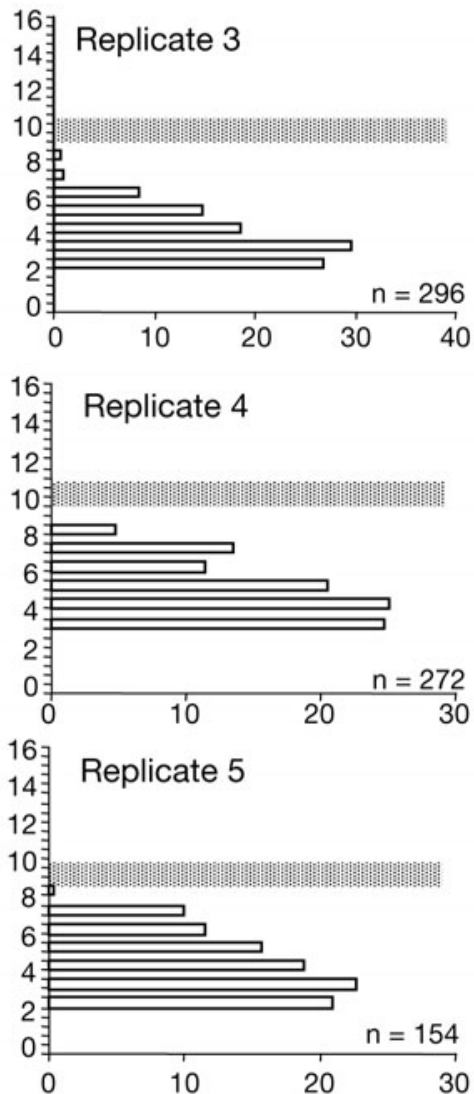

$5 \min$
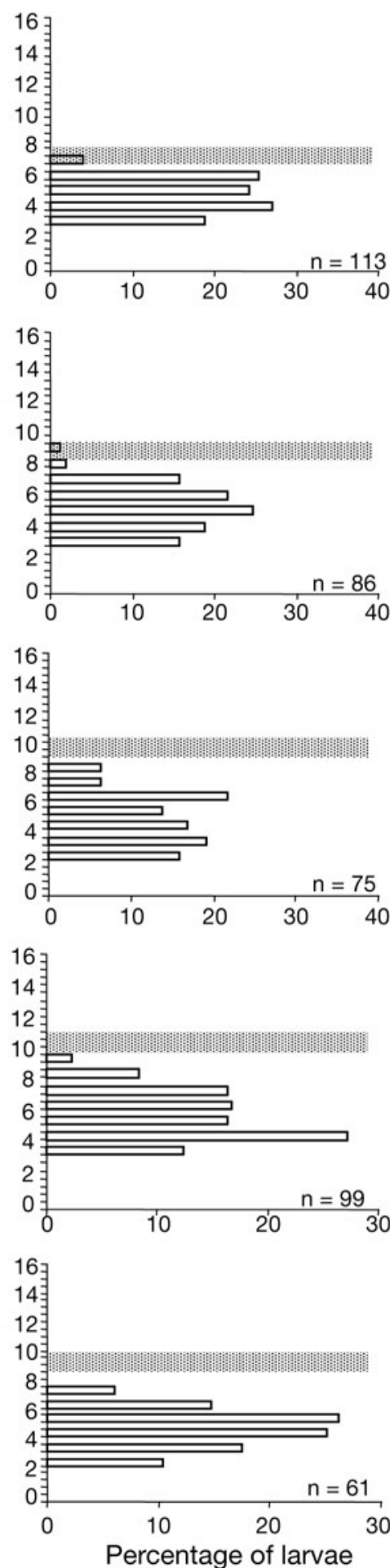

$10 \min$

$U\left(\mathrm{~cm} \mathrm{~s}^{-1}\right)$
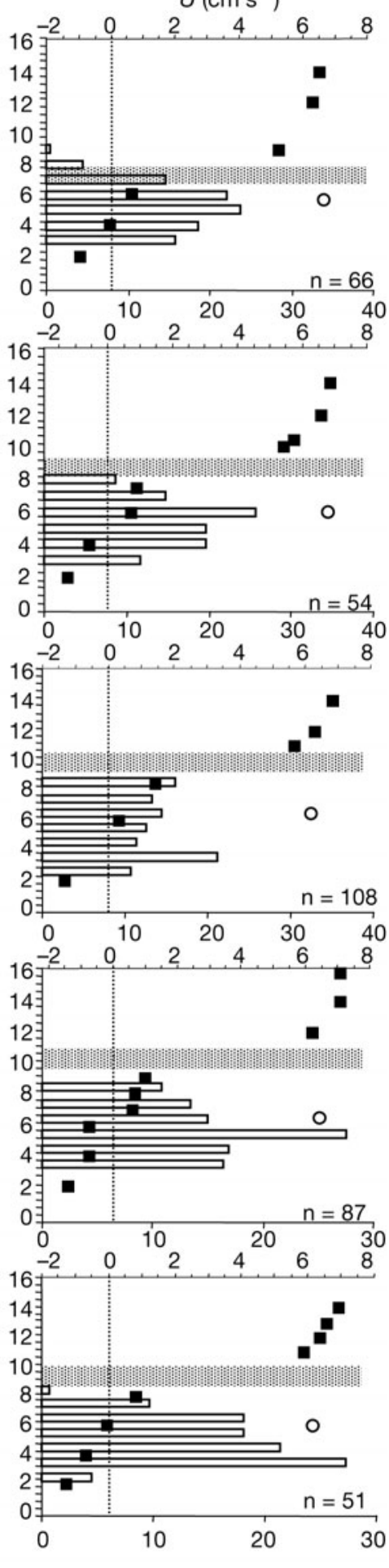

Fig. 4. Lytechinus variegatus. Vertical distribution of 4-arm larvae measured at $10.8 \mathrm{~m}$ downstream for each of 5 replicate runs of salt wedge with a salinity gradient of 21/31, at 1,5, and 10 min after larval introduction at $3 \mathrm{cab}$ and $11 \mathrm{~m}$ downstream. Shaded bar indicates estimated position of the halocline (see 'Materials and methods' for details). The vertical profile of alongstream velocity $U$ ( $\mathbf{\square}$; measured at $13 \mathrm{~m}$ downstream) is shown relative to larval distribution at $10 \mathrm{~min}$. O: mean height of center of mass of larval distribution. $\mathrm{n}=$ total number of larvae at $10 \mathrm{~min}$. Larval vertical distribution was dependent on time since introduction. Replicate 1: $\chi^{2}{ }_{12}=54.5, \mathrm{p}<0.0001$; Replicate 2: $\chi^{2}{ }_{12}=62.0, \mathrm{p}<0.0001$; Replicate 3: $\chi^{2}{ }_{12}=90.6, \mathrm{p}<0.0001$; Replicate 4: $\chi^{2}{ }_{12}=26.3$, $\mathrm{p}=0.01 ;$ Replicate $5: \chi^{2}{ }_{12}=0.576, \mathrm{p}=0.928$ 
25/31 $1 \mathrm{~min}$
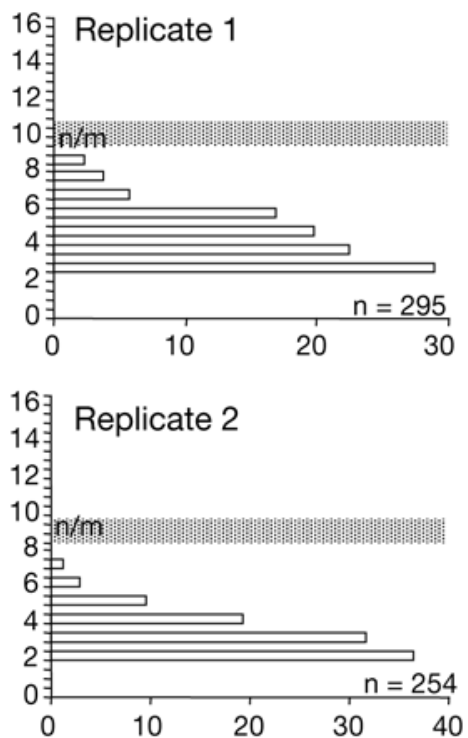

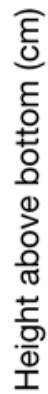
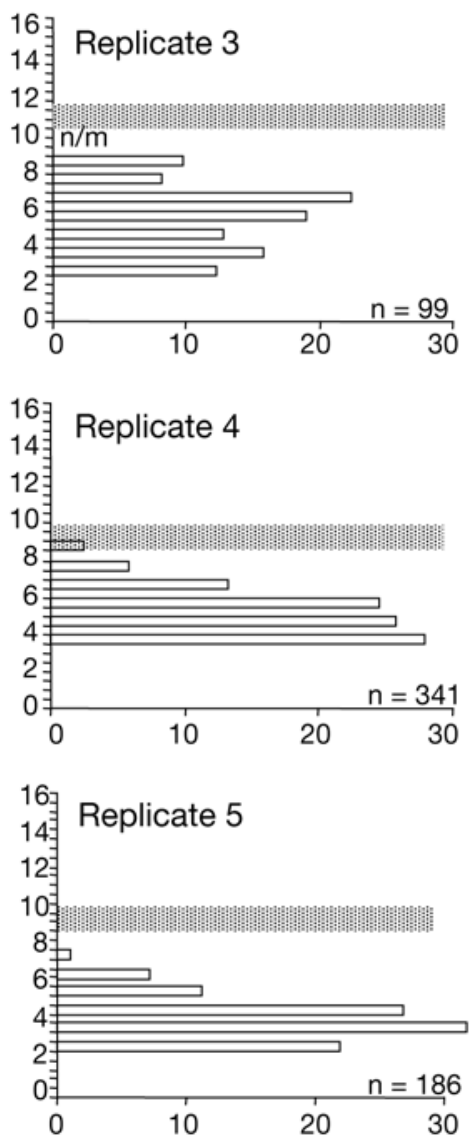

$5 \mathrm{~min}$
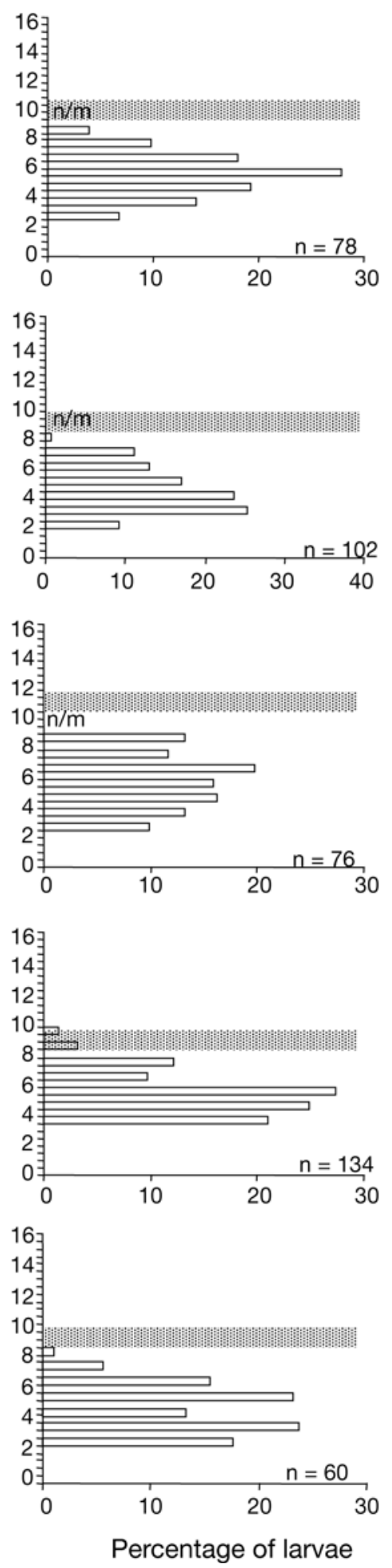
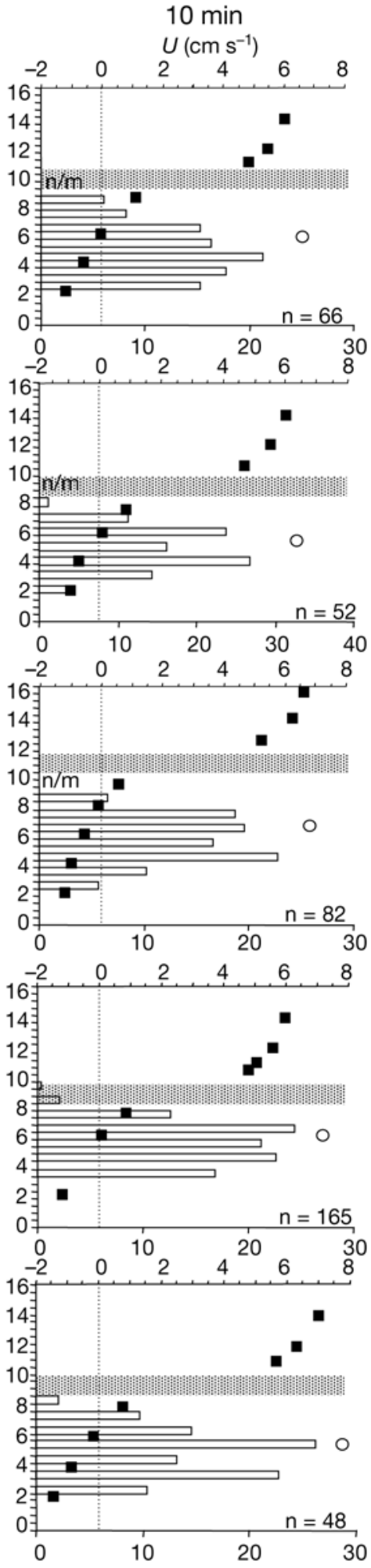

Fig. 5. Lytechinus variegatus. Vertical distribution of 4-arm larvae measured at $10.8 \mathrm{~m}$ downstream for each of 5 replicate runs of salt wedge with a halocline of 25/31, at 1,5, and 10 min after larval introduction at $3 \mathrm{cab}$ and $11 \mathrm{~m}$ downstream. Shaded bar indicates estimated position of the halocline (see 'Materials and methods' for details). The vertical profile of alongstream velocity $U(\boldsymbol{\square}$; measured at $13 \mathrm{~m}$ downstream) is shown relative to larval distribution at $10 \mathrm{~min}$. O: mean height of center of mass of larval distribution. $\mathrm{n}=$ total number of larvae at $10 \mathrm{~min}$. Larval vertical distribution was dependent on time since introduction. Replicate $1: \chi_{12}^{2}=41.9, \mathrm{p}<0.0001 ;$ Replicate $2: \chi_{12}^{2}=97.9, \mathrm{p}<0.0001$; Replicate $3: \chi_{12}^{2}=21.1, \mathrm{p}=0.007 ;$ Replicate $4: \chi^{2}{ }_{12}=28.2, \mathrm{p}=0.005$ Replicate 5: $\chi^{2}{ }_{12}=36.8, \mathrm{p}=0.0002$ 


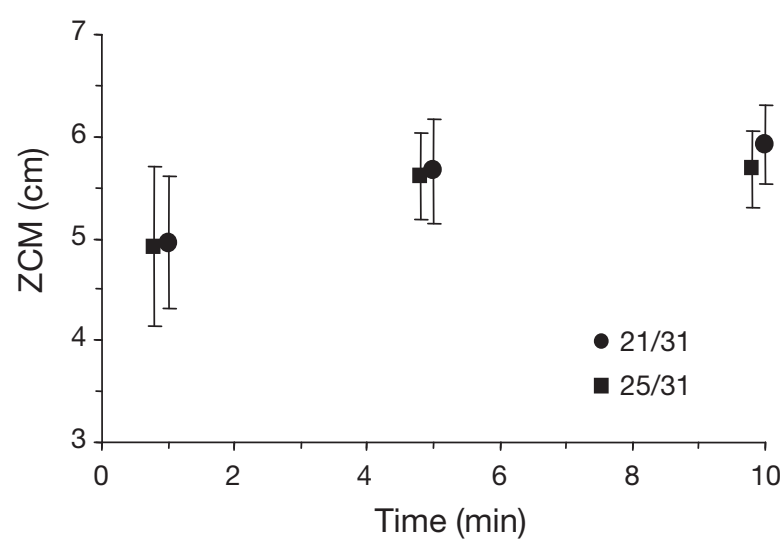

Fig. 6. Changes in the mean height of the center of mass $(\mathrm{ZCM} ; \pm \mathrm{SD}, \mathrm{n}=5)$ of larvae in relation to 2 haloclines $(21 / 31$, $25 / 31$ ) of salt wedges generated in a $17 \mathrm{~m}$ flume in the laboratory over the experimental period

\section{DISCUSSION}

We generated a salt wedge in a recirculating flume to examine the effects of the density and flow structure of the water column on larval vertical dispersal through haloclines. We used 2 haloclines (21/31 and 25/31) that were sharper (salinity change of 10 over 2 to $4 \mathrm{~cm}$ ) than those typically occurring in nature. This reproduced the density structure used in previous experiments done under 'no flow' for comparative purposes within the constraints of our experimental system (i.e. a minimum between-layer salinity difference of 6 to sustain a stable 2-layer flow). Measured salinity gradients in estuaries range from 0.8 over $31 \mathrm{~m}$ (Long Island Sound, NY, USA; Officer 1977) to 24.8 over 0.5 m (Palmiet estuary, Cape Province, South Africa; Largier \& Taljaard 1991). A salt wedge occurs in a highly stratified estuary with homogeneous flow within each water layer and a very sharp halocline (Rattray 1977). In the Mississippi river estuary, which is characterized by a typical salt wedge (Rattray 1977), the salinity gradient is 18 over $2.5 \mathrm{~m}$ (Wright \& Coleman 1971). The velocity difference between the 2 layers in our study was $\sim 8 \mathrm{~cm} \mathrm{~s}^{-1}$, and was also constrained by our experimental system. Typical velocity differences between the 2 layers in estuaries range between 10 and $110 \mathrm{~cm} \mathrm{~s}^{-1}$ (Officer 1977, Rattray 1977 , Largier \& Taljaard 1991).

In our experimental system, based on first-order estimates of Reynolds numbers (calculated as $\operatorname{Re}=\frac{U L}{\mathrm{~V}}$, where $U$ is the average velocity in each layer, $L$ is the thickness of the layer, and $v$ is the kinematic viscosity calculated for the average density $\rho$ of the layer), flow was laminar in both the bottom layer $(\mathrm{Re}=100$ to 200, $U=0.1$ to $0.3 \mathrm{~cm} \mathrm{~s}^{-1}, L=10 \mathrm{~cm}$ ) and the interface ( $\mathrm{Re}=$ 200 to $500, U=3 \mathrm{~cm} \mathrm{~s}^{-1}, L=1.5$ to $2.0 \mathrm{~cm}$ ), and it was laminar to transitional-to-turbulent in the upper water layer $\left(\operatorname{Re}=2000\right.$ to $2300, U=5.5$ to $\left.6 \mathrm{~cm} \mathrm{~s}^{-1}, L=5 \mathrm{~cm}\right)$. The 2-layer composite Froude numbers were 0.77 and 0.97, for 21/31 and 25/31, respectively, indicating that the interface was stable (calculated as

$$
F=\left(\left(\frac{u_{\mathrm{t}}^{2}}{g^{\prime} h_{\mathrm{t}}}\right)^{2}+\left(\frac{u_{\mathrm{b}}^{2}}{g^{\prime} h_{\mathrm{b}}}\right)^{2}\right)^{1 / 2}
$$

where $u_{\mathrm{t}}$ and $u_{\mathrm{b}}$ are mean velocities, and $h_{\mathrm{t}}$ and $h_{\mathrm{b}}$ are mean depths of the top and bottom layer, respectively, and $g^{\prime}$ is the reduced gravity). At critical values of $F>$ 1.0, waves form at the interface, which break and cause vertical mixing between the 2 layers (Wright \& Coleman 1971).

Larvae introduced into the flume at $3 \mathrm{cab}$ were displaced upstream, towards the observation area, because of the direction of $U$ at that height, and towards the interface because of negative geotaxis, typically shown by this species. Since $U$ at 2 to $4 \mathrm{cab}$ was $\sim 1$ to $1.5 \mathrm{~cm} \mathrm{~s}^{-1}$, larvae reached the observation area $\sim 50 \mathrm{~s}$ after introduction. Given vertical swimming speeds of $0.1 \mathrm{~cm} \mathrm{~s}^{-1}$, they also reached heights of $\sim 8 \mathrm{cab}$ over the same time interval (echinoid larvae at this age do not show positive geotaxis). Subsequently, larvae entered and exited the observation area horizontally because of advection in both alongstream directions and vertically because of entrainment into the less saline upper layer. Once larvae entered the upper layer where $U$ was $>2 \mathrm{~cm} \mathrm{~s}^{-1}$, they were advected alongstream towards the exit of the flume.

In the absence of flow, larval dispersal of Lytechinus variegatus was markedly inhibited by salinity differences of 6 and 10. Other studies have shown a similar inhibition of vertical dispersal of meroplanktonic larvae by the presence of a halocline (e.g. Vázquez \& Young 1996, Metaxas \& Young 1998b), indicating a behavioral response to a physicochemical feature in a static water column. The extent to which behavior will affect larval distributional patterns in the field, however, will greatly depend on the hydrodynamic regime.

In the presence of flow, larvae also aggregated below the halocline of the salt wedge. These aggregations appear to have been in part the result of a behavioral response to a perceived cue, such as a change in salinity. The gradual ascent of larvae towards the halocline, indicated by the change in vertical distribution over the first few minutes of observation, is consistent with echinoid larval behavior relative to a halocline observed in the absence of flow (e.g. Metaxas \& Young 1998b). In the region of larval aggregation, alongstream flow speed ranged between 0 and $1.5 \mathrm{~cm} \mathrm{~s}^{-1}$. The upper boundary of larval aggregation at or below the halocline could have resulted from larvae ceasing to swim upward in response to the salinity discontinu- 
ity at these slow speeds. In the benthic boundary layer, the swimming patterns of weak swimming cockle Cerastoderma edule larvae appear only partly affected (showing passive drift interspersed with controlled helical swimming) by flow at free-stream velocities of up to $2 \mathrm{~cm} \mathrm{~s}^{-1}$ (Jonsson et al. 1991). Luckenbach \& Orth (1992) showed that the powerfully swimming megalopae of the blue crab Callinectes sapidus behaviorly regulated both the direction and magnitude of travel in low flow speeds in a recirculating flume, but were passively advected in high flows.

In both 'no flow' and 'flow' experiments, the larval center of mass was positioned 2 to $4 \mathrm{~cm}$ below the lower boundary of the halocline, and in both cases it was lower in 25/31 than in 21/31. It should be noted that given the error associated with the exact location of the ORL and the pycnocline, the lower boundary of the discontinuity may have actually been slightly lower ( $\sim 1$ to $2 \mathrm{~cm})$ and, consequently, closer to the height of the larval center of mass than estimated. Given the limitations of our assumptions, we conclude that the positions of the larval center of mass were not detectably different between the 2 flow settings. However, the shapes of the larval vertical distributions were different between 'no flow' and 'flow' experiments. The bimodal distribution we observed under 'no flow' has been attributed in previous studies to an individual-based, rather than population-wide, adaptive behavioral response to environmental cues (e.g.

$>$ Burdett-Coutts \& Metaxas 2004). In contrast, under 'flow,' vertical distributions were unimodal with the peaks centered near the height of the center of mass. These differences in vertical distribution between 'no flow' and 'flow' experiments suggest an interaction between a larval behavioral response to the halocline and the flow regime.

In the salt wedge experiments, the observed larval distributions may have been the result of a combined larval behavioral response to some cue in the flow regime and to the halocline. In the region of larval aggregation, flow was laminar and sheared (because of a vertical gradient in horizontal velocity) both in the lower water layer and at the halocline, and there was a reversal in the direction of alongstream flow within the lower water layer. Molluscan larval swimming can be inhibited at shear rates $>3.5 \mathrm{~s}^{-1}$ (Jonsson et al. 1991, Fuchs et al. 2004). A first-order estimate suggests that shear rate (calculated as $\Delta U / \Delta z$ ) across the entire region of larval aggregation in our study was 0.3 to $1 \mathrm{~s}^{-1}$. Thus, it is unlikely that a behavioral response using shear as a cue was manifested at such low rates.

Alternatively, sheared flow may have compromised the directional swimming ability of the larvae and enhanced the probability of retention within the region below the halocline, resulting in a unimodal distribu- tion. In shear, unequal forces applied across the larval echinoid body can disrupt the passive stability of the upward-moving larvae, causing them to tilt (Grünbaum \& Strathmann 2003). As long as they do not cease swimming, the re-oriented larvae can most likely continue to maneuver by reversing their ciliary currents (Strathmann \& Grünbaum 2006). In our study, the continuous re-orientation of larvae in sheared flow coupled with their continued maneuvering could have resulted in downward swimming away from the discontinuity. Similarly, shear experienced by downwardswimming larvae when they enter the area of reversed flow will cause them to re-orient once again and resume their upward swimming. This continuous larval re-orientation can promote larval aggregation within the $6 \mathrm{~cm}$ region below the halocline and decrease the probability of larval entrainment into the halocline and the overlying, low-salinity layer.

We have shown that larval aggregation relative to a halocline can occur under low horizontal flow velocities, as in static conditions. We propose that the aggregations were formed as result of a larval behavioral response to the halocline. However, flow characteristics, such as shear, can modify the overall shape of the larval vertical distribution relative to the halocline, by reducing the probability of larval penetration into the discontinuity and of their subsequent entrainment into the layer of lower salinity. In the field, features of discontinuity in the water column, such as fronts and pycnoclines, may provide larvae with cues about the quality of their environment. Larvae that are able to respond to such cues, even on short-time scales (tens of minutes), are more likely to remain within habitats that are favorable to their survival.

Acknowledgements. We thank W. R. Geyer, R. E. Scheibling, and C. A. Zimmer for extensive discussions. A. Logan (neé Roy) conducted all video analyses. H. Chapman, H. L. Hunt, and S. Mills helped with larval rearing and experiments. E. Scheibling applied his artistry in Fig. 1. K. Helfrich loaned us the T-S microprobe. Funding was provided by a grant from the Rinehart Coastal Research Center, WHOI, a Discovery grant from NSERC Canada to A.M., and grant OCE-969105 from the US NSF to L.M.

\section{LITERATURE CITED}

Burdett-Coutts V, Metaxas A (2004) The effect of the quality of food patches on larval vertical distribution of the sea urchins Lytechinus variegatus (Lamarck) and Strongylocentrotus droebachiensis (Mueller). J Exp Mar Biol Ecol 308:221-236

Butman CA (1987) Larval settlement of soft-sediment invertebrates: the spatial scales of pattern explained by active habitat selection and the emerging role of hydrodynamics. Oceanogr Mar Biol Annu Rev 25:113-165

Butman CA, Chapman RJ (1989) The 17-meter flume at the Coastal Research Laboratory. Part I: Description and user's 
manual. CRC-89-2, WHOI-89-10. Coastal Research Center, Woods Hole Oceanographic Institution, Woods Hole, MA

Fuchs HL, Mullineaux LS, Solow A (2004) Sinking behavior of gastropod larvae (Ilyanassa obsoleta) in turbulence. Limnol Oceanogr 49:1937-1945

Gallager SM, Davis CS, Epstein AW, Solow A, Beardsley RC (1996) High-resolution observations of plankton spatial distributions correlated with hydrography in the Great South Channel, Georges Bank. Deep Sea Res II 43: $1627-1663$

Grünbaum D, Strathmann RR (2003) Form, performance and trade-offs in swimming and stability of armed larvae. J Mar Res 61:659-691

Harder W (1968) Reactions of plankton organisms to water stratification. Limnol Oceanogr 13:156-168

Jonsson PR, André C, Lindegarth M (1991) Swimming behaviour of marine bivalve larvae in a flume boundary-layer flow: evidence for near-bottom confinement. Mar Ecol Prog Ser 79:67-76

Largier JL, Taljaard S (1991) The dynamics of tidal intrusion, retention, and removal of seawater in a bar-built estuary. Estuar Coast Shelf Sci 33:325-338

Luckenbach MW, Orth RJ (1992) Swimming velocities and behavior of blue crab (Callinectes sapidus Rathbun) megalopae in still and flowing water. Estuaries 15:186-192

Mann R, Campos BM, Luckenbach MW (1991) Swimming rate and responses of larvae of three mactrid bivalves to salinity discontinuities. Mar Ecol Prog Ser 68:257-269

McConnaughey RA, Sulkin SD (1984) Measuring the effects of thermoclines on the vertical migration of larvae of Callinectes sapidus (Brachyura: Portunidae) in the laboratory. Mar Biol 81:139-145

Metaxas A (2001) Behaviour in flow: perspectives on the distribution and dispersion of meroplanktonic larvae in the water column. Can J Fish Aquat Sci 58:86-98

Metaxas A, Young CM (1998a) Responses of echinoid larvae to food patches of different algal densities. Mar Biol 130: $433-445$

Metaxas A, Young CM (1998b) Behaviour of echinoid larvae around sharp haloclines: effects of the salinity gradient and dietary conditioning. Mar Biol 131:443-459

Mullineaux LS, Butman CA (1991) Initial contact, exploration and attachment of barnacle (Balanus amphitrite) cyprids settling in flow. Mar Biol 110:93-103

Officer CB (1977) Longitudinal circulation and mixing relations in estuaries. In: Estuaries, geophysics, and the envi- ronment. Studies in geophysics. National Academy of Sciences, Washington, DC, p 13-21

Pineda J (1994) Internal tidal bores in the near-shore: warmwater fronts, seaward gravity currents and the onshore transport of neustonic larvae. J Mar Res 52:427-458

Pineda J (1999) Circulation and larval distribution in internal tidal bore fronts. Limnol Oceanogr 44:1400-1414

Raby D, Lagadeuc Y, Dodson JJ, Mingelbier M (1994) Relationship between feeding and vertical distribution of bivalve larvae in stratified and mixed waters. Mar Ecol Prog Ser 103:275-284

Rattray M Jr (1977) Fjord and salt-wedge circulation. In: Estuaries, geophysics, and the environment. Studies in geophysics. National Academy of Sciences, Washington, DC, p 36-45

Shanks AL, Largier J, Brink L, Brubaker J, Hooff R (2000) Demonstration of the onshore transport of larval invertebrates by the shoreward movement of an upwelling front. Limnol Oceanogr 45:230-236

Strathmann RR, Grünbaum D (2006) Good eaters, poor swimmers: compromises in larval form. Integr Comp Biol 46: 312-322

Sulkin SD, Van Heukelem WF, Kelly P (1983) Behavioral basis of depth regulation in hatching and post-larval stages of the mud crab Eurypanopeus depressus. Mar Ecol Prog Ser 11:157-164

Thiébaut E, Dauvin JC, Lagadeuc Y (1992) Transport of Owenia fusiformis larvae (Annelida: Polychaeta) in the Bay of Seine. I. Vertical distribution in relation to water column stratification and ontogenetic vertical migration. Mar Ecol Prog Ser 80:29-39

Tremblay MJ, Sinclair M (1990a) Sea scallop larvae Placopecten magellanicus on Georges Bank: vertical distribution in relation to water column stratification and food. Mar Ecol Prog Ser 61:1-15

Tremblay MJ, Sinclair M (1990b) Diel vertical migration of sea scallop larvae Placopecten magellanicus in a shallow embayment. Mar Ecol Prog Ser 67:19-25

Trowbridge JH, Geyer WR, Butman CA, Chapman RJ (1989) The 17-meter flume at the Coastal Research Laboratory. Part II: flow characteristics. CRC-89-3, WHOI-89-11. Coastal Research Center, Woods Hole Oceanographic Institution, Woods Hole, MA

> Vázquez E, Young CM (1996) Responses of compound ascidian larvae to haloclines. Mar Ecol Prog Ser 133:179-190

> Wright LD, Coleman JM (1971) Effluent expansion and interfacial mixing in the presence of a salt wedge, Mississippi River Delta. J Geophys Res 76:8649-8661

Submitted: May 20, 2008; Accepted: November 17, 2008

Proofs received from author(s): February 15, 2009
Editorial responsibility: Steven Morgan,

Bodega Bay, California, USA 